\title{
Exosomal microRNA-107 reverses chemotherapeutic drug resistance of gastric cancer cells through HMGA2/mTOR/P-gp pathway
}

\author{
Lu Jiang ${ }^{1}$, Yan Zhang ${ }^{1}$, Linghui Guo ${ }^{1}$, Chaoyang Liu' ${ }^{1}$ Pan Wang ${ }^{2}$ and Weihong Ren ${ }^{3 *}$
}

\begin{abstract}
Background: RNA cargo in exosomes, especially microRNAs (miRNAs), play an important role in the chemotherapy drug resistance of human cancers. However, the role and mechanism of exosomal miR-107 on multidrug resistance of gastric cancer cells was still not clear. In this study, we sought to explore whether exosomal miR-107 could reverse the resistance of gastric cancer cells to the chemotherapy drugs.

Methods: We extracted exosomes from sensitive (SGC-7901, MGC-803) and resistant (SGC-7901/5-FU) gastric cancer cells by ultracentrifugation and the isolated exosomes were identified using transmission electron microscopy (TEM) and dynamic light scattering analysis (DLS). The expression of miR-107 and high mobility group A2 (HMGA2) were detected by real-time quantitative PCR (RT-qPCR). MTT assay was used to investigate the effect of exosomes on gastric cancer cells growth in vitro. The uptake of exosomes by recipient cells were observed using a fluorescence microscope. The predicted target relationship between miR-107 and HMGA2 was verified by gauss-luciferase reporter assay. The expression of HMGA2, p-mTOR/mTOR, P-gp and other exosomal indicated marker proteins was detected by western blot.
\end{abstract}

Results: Our results indicated that the isolated exosomes were typically cup-like lipid bilayer membranes structure. SGC-7901/5-FU cells were cross-resistant to chemotherapy drug cisplatin (CDDP), and the sensitive cells-secreted exosomes drastically reversed the resistance of the resistant GC cells to the chemotherapeutic drugs, which was verified by exosomal inhibitor GW4896. Mechanistically, the reversal effect was mainly mediated by exosome-secreted miR-107 through downregulating the expression of target molecular HMGA2 and inhibiting HMGA2/mTOR/P-gp pathway, which were supported by results from luciferase reporter assay and rescue assay.

Conclusions: These findings demonstrated that exosome-transmitted miR-107 significantly enhanced the sensitivity of resistant gastric cancer cells to chemotherapeutic agents by mediating the HMGA2/mTOR/P-gp axis and exosomal miR-107 may be a novel target in gastric cancers treatment.

Keywords: Gastric cancer, Reverse drug resistance, Exosomal miR-107, HMGA2/mTOR/P-gp

*Correspondence: ren_weihong@163.com

${ }^{3}$ Department of Clinical Laboratory, The First Affiliated Hospital of Henan

University of Chinese Medicine, 19 Renmin Road, Zhengzhou 450000,

China

Full list of author information is available at the end of the article

\section{Background}

Gastric cancer (GC) is the fifth most common malignant tumor in the world and the third leading cause of cancer-related deaths, posing a serious threat to human life and health [1]. Due to the lack of effective biomolecular 
markers, GC is usually diagnosed at an advanced stage, and its 5 -year survival rate is about $20-30 \%[2,3]$. Various factors including genetics, epigenetics and environment could affect the occurrence and progression of GC [4]. At the present stage, there is still lacking of effective treatment methods in the clinical treatment of advanced gastric cancer, although targeted therapy or a combination of targeted therapy and chemotherapy could improve the effect to a certain extent, surgery and chemotherapy are still the major approaches for treatment. The chemotherapy drugs 5-Fluorouracil, cisplatin, doxorubicin and paclitaxel are commonly used for GC treatment, which inevitably led to chemotherapy drug resistance [5]. Therefore, exploring the mechanism of drug resistance in GC is urgently needed clinically, and would make it possible for development of clinical treatment of resistant GC.

Exosomes are a class of extracellular vesicles with 30-150 $\mathrm{nm}$ in diameter, and have a lipid bilayer structure, which are similar to plasma membranes. The membrane has a variety of proteins (CD9, CD63, CD81 and integrin, etc.) and lipids (ceramide, phosphatidylethanolamine, phosphatidylserine, etc.), and there are also a variety of nucleic acids (mRNA, miRNA, LncRNA, circRNA and DNA) and proteins (TSG101, Alix, Hsc70 and Hsp90, etc.) inside of exosomes [6]. Exosomes could transport a variety of biologically active molecules (such as nucleic acids, lipids, and proteins) to the recipient cells by binding to the recipient cells. Exosomes mediate the information exchange between cells, and regulate a variety of cellular physiological and pathological processes [7]. Expecially, due to the lipid membranes, the exosomal miRNAs are protected from being damaged by cellular environment. Many studies have reported cancer cellsderived exosomal miRNAs played important roles in mediating cellular immune response and tumor angiogenesis, drug resistance and metastasis $[8,9]$. Some literatures demonstrated that a variety of exosomal miRNAs could regulate chemotherapy resistance of cancer cells $[10,11]$.

MicroRNA-107 was a new non-coding RNA discovered in recent years, several studies have illustrated that miRNA-107 played an important role in various diseases process, such as cancers, Alzheimer's disease, and osteoarthritis [12-14]. Although there were studies showing that the sensitivity of resistant non-small cell lung cancer cells and breast cancer cells to chemotherapy drug paclitaxel could be regulated by miRNA-107 [15, 16], also the expression level of miRNA-107 might be an effective biomarker for poor prognosis of GC patients [17], whether exosomal miR-107 also regulates on multidrug resistance of cancer cells has not been elucidated, and the detailed underlying mechanisms of how exosomal miR-107 regulates the sensitivity of cancer cells to the chemotherapeutic drugs remain largely unknown.

In this study, we sought to explore the effects of exosomal miR-107 on chemotherapeutic drug-resistance and found that exosomal miR-107 extracted from sensitive GC cells could increase the sensitivity of resistant GC cells. We also identified that the target molecules of exosomal miR-107 was HMGA2, which was a small nonhistone nuclear protein, and a framework transcription factor. HMGA2 could change the DNA conformation, or directly interact with related proteins, and enhance or inhibit the transcription of the genes through binding to the chromatin enriched AT sequences via its AT hook structure [18]. Our results showed that the reversal effect of exosomal miR-107 on resistant GC was mediated by regulating the expression of target molecular HMGA2, the activity of mTOR and the expression of P-gp.

\section{Materials and methods \\ Cell viability analysis}

5-FU sensitive/resistant human gastric cancer cell line SGC-7901 and CDDP sensitive/resistant human gastric cancer cell line SGC-7901 (both from Huiying BioTech), MGC-803 human gastric cancer and HEK $293 \mathrm{~T}$ cell lines (both from Beina BioTech), were maintained in RPMI-1640 and DMEM-H medium (Sigma-Aldrich), supplemented with $10 \% \mathrm{FBS}$ at $37^{\circ} \mathrm{C}$ in a humidified atmosphere with $5 \% \mathrm{CO} 2$, respectively. Different concentrations of 5-FU or cisplatin (Meilun BioTech) were used to treat the cells. After $48 \mathrm{~h}$ incubation, cells were subjected to MTT analysis and the absorbance at $570 \mathrm{~nm}$ was recorded by a Spectra Max i3 microplate reader (Molecular Devices Corp., Sunnyvale, CA, USA).

\section{Exosome isolation}

The SGC-7901 and SGC-7901/5-FU GC cells were cultured in 1640 medium containing 10\% exosomefree fetal bovine serum (FBS), and exosomes were extracted by ultracentrifugation method. The collected cell supernatant was centrifuged at $300 \times \mathrm{g}$ for $10 \mathrm{~min}, 2000 \times \mathrm{g}$ for $20 \mathrm{~min}, 10,000 \times \mathrm{g}$ for $20 \mathrm{~min}$, respectively. Then it was filtered by a $0.22 \mu \mathrm{M}$ filter and centrifuged at $3500 \times \mathrm{g}$ for $5 \mathrm{~min}$ in ultrafiltration tubes. Gradient centrifugation was performed for the concentrated supernatant: $80,000 \times \mathrm{g} / 40 \mathrm{~min}$, $80,000 \times \mathrm{g} / 80 \mathrm{~min}, 110,000 \times \mathrm{g} / 40 \mathrm{~min}, 110,000 \times \mathrm{g} / 80 \mathrm{~min}$, $110,000 \times \mathrm{g} / 120 \mathrm{~min}, \quad 140,000 \times \mathrm{g} / 40 \mathrm{~min}$, $140,000 \times \mathrm{g} / 80 \mathrm{~min}, 140,000 \times \mathrm{g} / 120 \mathrm{~min}$ at $4{ }^{\circ} \mathrm{C}$. Finally, exosomes were washed and resuspended by PBS. The diameter of exosomes was detected by dynamic light scattering (DLS) as described below. The concentration of exosomes was measured by BCA protein assay kit. 


\section{Transmission electron microscopy}

The morphology and size of exosomes was observed by a transmission electron microscopy (JEM-1400, Tokyo, Japan). The experiment was performed by a professional technician from the Electron Microscopy Center of Henan University of Traditional Chinese Medicine. Fifteen microliters of the prepared exosomes, positive (pure milk) and negative $\left(\mathrm{ddH}_{2} \mathrm{O}\right)$ controls were pipetted onto carbon-coated copper grids, incubated for $150 \mathrm{~s}$ and excess fluids were wiped off. The absorbed exosomes were stained with $3 \%$ uranyl acetate for $3 \mathrm{~min}$, washed with $\mathrm{ddH}_{2} \mathrm{O}$, air-dried for $2 \mathrm{~h}$, and analyzed with a transmission electron microscope at $80-120 \mathrm{kV}$ voltage.

\section{Dynamic light scattering analysis}

A NanoBrook Zetasizer 90Plus PALS (Nano ZS) (Malvern, UK) was applied for dynamic light scattering. Isolated exosome samples were diluted in PBS. All samples were measured with parameters of using a helium/neon laser $(640 \mathrm{~nm})$ at $220 \mathrm{~V}$ voltage, a temperature of $25^{\circ} \mathrm{C}$ and an angle of $90^{\circ}$. The exosome size refers to the scattering intensity distribution (z-average) and effective diameter size calculated based on scattering intensity.

\section{Exosomal uptake PKH26 staining}

Exosomes derived from SGC-7901 cells were labelled with PKH26 kit (PKH26 Red Fluorescent Cell Linker Kit, Sigma, USA). $50 \mu \mathrm{L}$ ultracentrifugation exosomes suspended in PBS were added with $100 \mu \mathrm{L}$ Solution C. $0.5 \mu \mathrm{L}$ PKH26 was dissolved in another $100 \mu \mathrm{L}$ solution C. The diluted exosomes were added to the diluted PKH26 rapidly, mixed and incubated for $5 \mathrm{~min}$, and $250 \mu \mathrm{L}$ sterile FBS was added to stop staining. The exosomes labelled with PKH26 were isolated using ExoQuick ${ }^{\mathrm{TM}}$ Exosome Isolation Reagent (SBI, USA). $200 \mu$ g exosomes labelled with PKH26 were added to SGC-7901/ADR cells. After $24 \mathrm{~h}$, the SGC-7901/ADR cells were fixed by $4 \%$ paraformaldehyde, stained with DAPI, and washed with PBS for three times. Fluorescence signal of PKH26 was observed under a Carl Zeiss LSM710 laser scanning confocal microscope (Oberkochen, Germany).

\section{Transwell coculture}

A stable MGC-803 cell line with exosomes labeled with green fluorescence (MGC-803/pLVX-CD63-AcGFP1) was constructed by our laboratory. MGC-803 cells line or MGC-803-pLVX stable cells line $(4 \times 105 /$ well $)$ were seeded in the upper chamber of a coculture system with a $0.4 \mu \mathrm{m}$ pore membrane, and the recipient SGC-7901/5-FU $(2 \times 105 /$ well $)$ were placed in the lower chamber. All cells were incubated in medium with $10 \%$ exosome-free FBS. After $48 \mathrm{~h}$ of coculture, SGC-7901/5-FU cells were observed under a fluorescence microscope, or collected, washed with PBS, resuspended in $500 \mu \mathrm{l}$ of PBS and the fluorescence signal were detected by FACS Aria II flow cytometry (Becton Dickinson, USA).

\section{GW4869 treatment}

GW4869, an inhibitor for the exosome formation and release $[19,20]$, was firstly dissolved in DMSO into a stock solution of $1.5 \mathrm{mM}$, then added with $5 \%$ methanesulfonic acid to increase the solubility in DMSO. SGC7901 cells were treated with GW4869 at a final concentration of $10 \mu \mathrm{M}$ for $24 \mathrm{~h}$.

\section{miRNA inhibitor, siRNA and plasmid vectors transfection} SGC-7901 cells were transfected with a miR-107 inhibitor (the sequences were 5'-UGAUAGCCCUGUACA AUGCUGCU-3') or miR-107 inhibitor negative control (the sequences were 5'-CAGUACUUUUGUGUAGUA CAA- $3^{\prime}$ ) at $100 \mathrm{nM}$ with Lipofectamine 2000 (invitrogen, CA, USA). Three siRNAs targeting HMGA2 and negative control were synthesized. The siRNA with the highest gene silencing efficacy was chosen for further use. All the miRNA (inhibitor or mimic) and siRNA were synthesized by Shanghai Sangon Biotech (Shanghai, China). Co-transfection of $50 \mathrm{nM}$ miR-107 inhibitor and $50 \mathrm{nM}$ HMGA2 siRNA were included. pEX-HMGA2-WT and HMGA2 deletion mutant pEX-HMGA2-MUT43 (43-109 aa were deleted, including the central and the last AThook DNA binding domains) plasmid vectors [21] were synthesized by Shanghai Gene Pharma Co. Ltd. (Shanghai, China).

\section{Luciferase reporter assay}

The targeted binding site of miR-107 to HMGA2 was predicted using TargetScan (http://www.targetscan. org/vert_72/). HMGA2 wild-type (insert sequence: 5'-gtcTAGTACTTATTAC-ATGCTGCt- $3^{\prime}$ ) and mutanttype (insert sequence: $5^{\prime}$-gtcTAGTACTTATTACTACGA CGt-3') expression vectors were cloned into a Gaussia luciferase (GLuc) reporter vector (pEZX-MT05, Genecopoeia), which contains a reference gene called secreted alkaline phosphatase (SeAP). The HEK $293 \mathrm{~T}$ cells in 24-well plates were co-transfected with the above wild or mutant reporter vectors with miR-107 mimic or NC using transfection reagent Lipofectamine 2000 for $48 \mathrm{~h}$. The activities of GLuc and SeAP were quantified with the secrete-pair dual luminescence assay kit (Genecopoeia).

\section{Western blotting analysis}

Protein extraction of exosomes and cells as well as Western blot analysis were performed according to our 


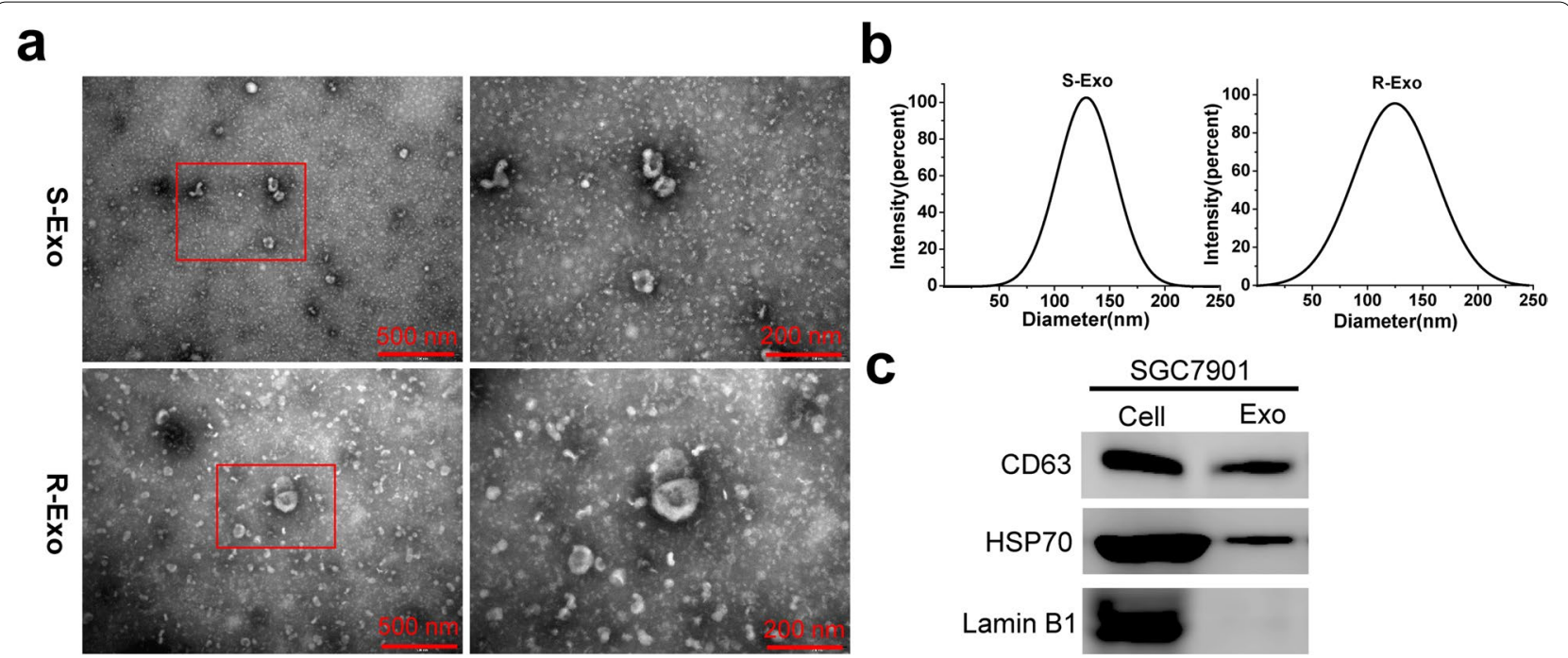

Fig. 1 Characteristics of exosomes derived from SGC-7901 and SGC-7901/5-FU GC cells. a The transmission electron micrograph showed round-shaped vesicles with bilayer membranes ranging from $30 \mathrm{~nm}$ to $180 \mathrm{~nm}$ in diameter released by SGC-7901 (S-EXo) and SGC-7901/5-FU (R-Exo) cells. Scale bar $=500 \mathrm{~nm}$ and $200 \mathrm{~nm}$, respectively. b Dynamic light scattering analysis (DLS) indicated that the dominant size of S- and R-Exo was about $120 \mathrm{~nm}$. c The positive markers of exosomes, CD63 and HSP70, were detected in S- and R-Exo by Western blot

previous study [22]. The following antibodies were used: anti-Lamin B1 (\#13435, 1:1000), anti-HSP 70 (\#4872, 1:1000), anti-p-mTOR (\#5536, 1:1000), anti-mTOR (\#2983, 1:1000), anti-P-gp (\#13342, 1:500) (All from Cell Signaling); anti-CD63 (D360973, 1:500) and antiHMGA2 (D160487, 1:500) (Both from BBI) and antiGAPDH (CW0100, 1:1000, Beijing Com Win).

\section{Quantitative PCR analysis}

mRNA extraction of cells as well as the relative mRNA level of HMGA2 gene analyzed by quantitative PCR were performed according to our previous study [22]. The primer sequences for HMGA2 were 5'-TGGGAGGAG CGAAATCTAA-3' (sense) and 5'-GGTGAACTCAAG CCGAAG-3' (antisense) and the primer sequences for the control gene GAPDH were 5'-CGCTGAGTACGT CGTGGAGTC-3' (sense) and 5'-GCTGATGATCTT GAGGCTGTTGTC-3' (antisense). Total microRNA was extracted from cells and exosomes using miRNA Purification kit (CW0627S, Beijing Com Win), microRNA (100 300 ng) was reverse transcribed into cDNA by using miRNA cDNA Synthesis kit (CW2141S, Beijing Com Win), and the relative level of miR-107 was determined by qPCR using miRNA qPCR Assay kit (CW2142S, Beijing Com Win). The relative expression of miR-107 was normalized to U6, and the antisense primers of miR-107 and U6 were provided by the above kit. The sense primer sequences for miR-107 were $5^{\prime}$ - CGC AGCAGCATTGTACAGGGCTATCA-3' and the sense primer sequences for U6 were 5'-CCGAGAGAAGAT TAGCATGGCCCCTG-3'.

\section{Statistics}

All experiments were repeated at least three times except that some WB experiments were repeated twice. A oneway analysis of variance (ANOVA) followed by Dunnett's test was used for multiple comparisons.

Values of $P<0.05$ were considered significant, and values of $P<0.01$ were considered extremely significant. All data expressed as mean \pm SD unless otherwise indicated.

\section{Results}

Isolation and Characterization of exosomes derived from SGC-7901 and SGC-7901/5-FU GC cells were isolated and confirmed.

In order to study the effects of exosomes on the sensitivity of SGC-7901 GC cells to chemotherapy, we used ultracentrifugation to extract the exosomes of SGC-7901 and SGC-7901/5-FU cells. It can be observed that the vesicles of sensitive and resistant SGC-7901 cells were goblet-shaped with bilayer membranes, and the diameter ranged from $30 \mathrm{~nm}$ to $180 \mathrm{~nm}$ (Fig. 1a). some proteins were also found in the background under the transmission electron microscope.

The size and diameter of dominant exosomes were further analyzed by DLS. The results showed that the particle sizes were normally distributed around $120 \mathrm{~nm}$ (Fig. 1b). Through western blot analysis, the exosomal marker proteins CD63 and HSP70 were detected in the 
exosomes, while the nuclear marker protein Lamin B1 was mainly enriched in the whole cell lysates (Fig. 1c). These results indicated that the vesicles extracted from sensitive and resistant SGC-7901 cells exhibited typical exosomal characteristics.

SGC-7901/5-FU cells were resistant to chemotherapy drugs 5-fluorouracil and cisplatin

We first determined the drug sensitivity of SGC-7901, MGC-803 sensitive cells and SGC-7901/5-FU resistant cells to the chemotherapy drugs 5-fluorouracil (5-FU) and cisplatin (CDDP). As shown in Fig. 2, the SGC7901/5-FU cell lines were resistant to 5-FU and also cross-resistant to CDDP compared with SGC-7901 and MGC-803 sensitive cells. The $\mathrm{IC}_{50}$ values of 5 -FU and CDDP in the SGC-7901/5-FU were about ten times more than that in the SGC-7901 and MGC-803 cells.

The exosomes isolated from SGC-7901 and MGC-803 cells increased the sensitivity of SGC-7901/5-FU and SGC-7901/ CDDP cells to 5-FU and CDDP

In order to explore whether exosomes could modulate the sensitivity of GC resistant cells to chemotherapy drug, we extracted the exosomes of SGC-7901 and MGC-803 sensitive cells, and treated SGC-7901/5-FU drug-resistant cells with the exosomes at a certain dose. The results showed that exosomes extracted from MGC-803 and SGC-7901 increased the sensitivity of SGC-7901/5-FU cells to 5-FU and CDDP. In the presence of MGC-803and SGC-7901-secreted exosomes, the $\mathrm{IC}_{50}$ values $(\mu \mathrm{M})$ of 5-FU in the SGC-7901/5-FU resistant cells decreased from 3023.60 to 1718.14 and 1020.82 , respectively, and the $\mathrm{IC}_{50}$ values $(\mu \mathrm{M})$ of CDDP in the SGC-7901/5-FU resistant cells decreased from 146.22 to 116.46 and 82.85 , respectively. What's more, the effects of exosomes from SGC-7901 cells were much stronger than those from MGC-803 cells. The $\mathrm{IC}_{50}$ values of 5 -FU and CDDP of SGC-7901/5-FU cells treated with SGC-7901 exosomes were about 33 and $57 \%$ of those without exosomes treatment, respectively (Fig. 3).

In addition, we treated SGC-7901/CDDP drug-resistant cells with the exosomes isolated from SGC-7901 cells and the $\mathrm{IC}_{50}$ values of CDDP in the SGC-7901/CDDP resistant cells decreased from $169.01 \mu \mathrm{M}$ to $89.66 \mu \mathrm{M}$ (Additional file 1: Fig. S1). Altogether, the exosomes isolated from sensitive $\mathrm{GC}$ cells reversed the resistance of SGC-7901/5-FU and SGC-7901/CDDP cells to the chemotherapeutic agents.

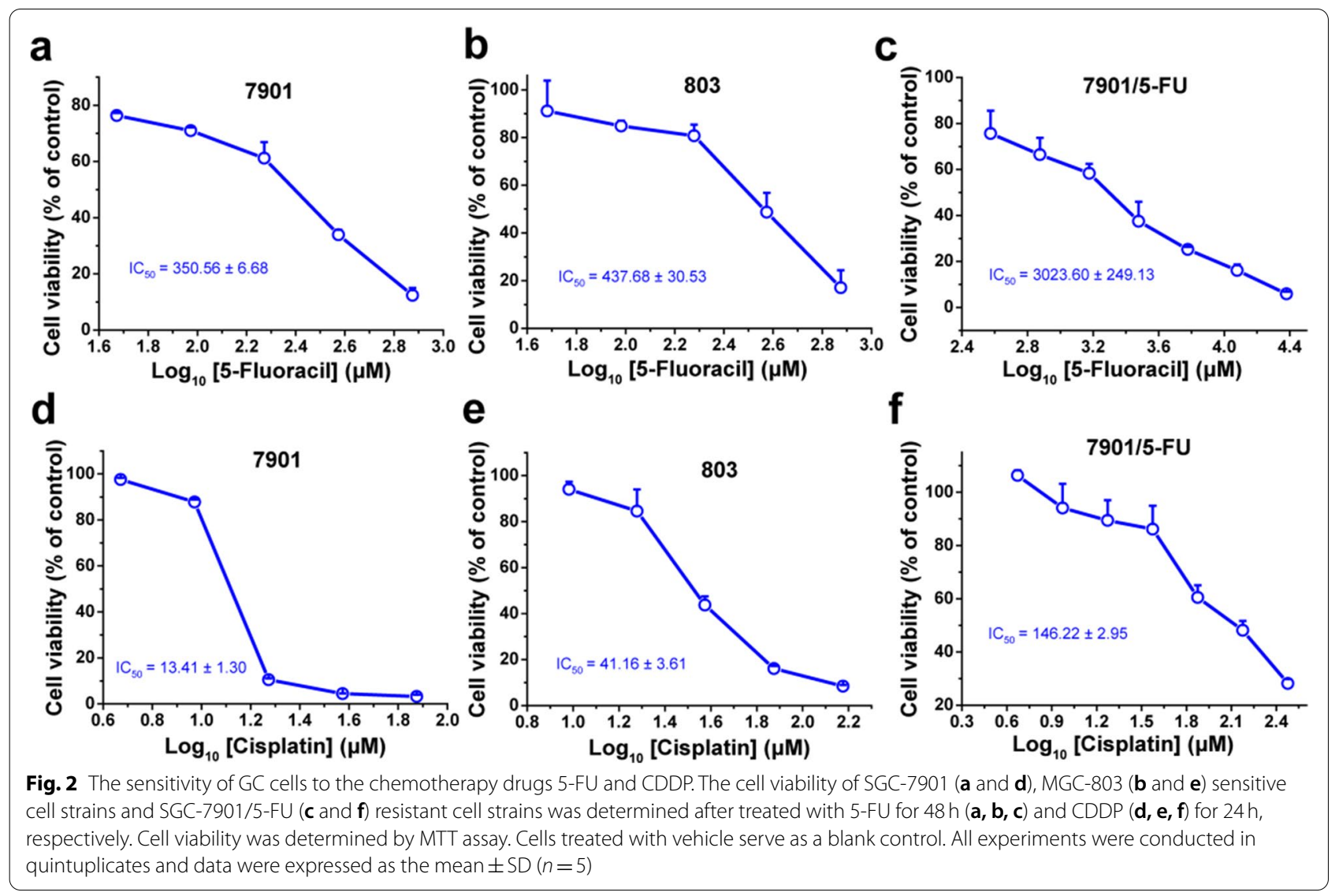



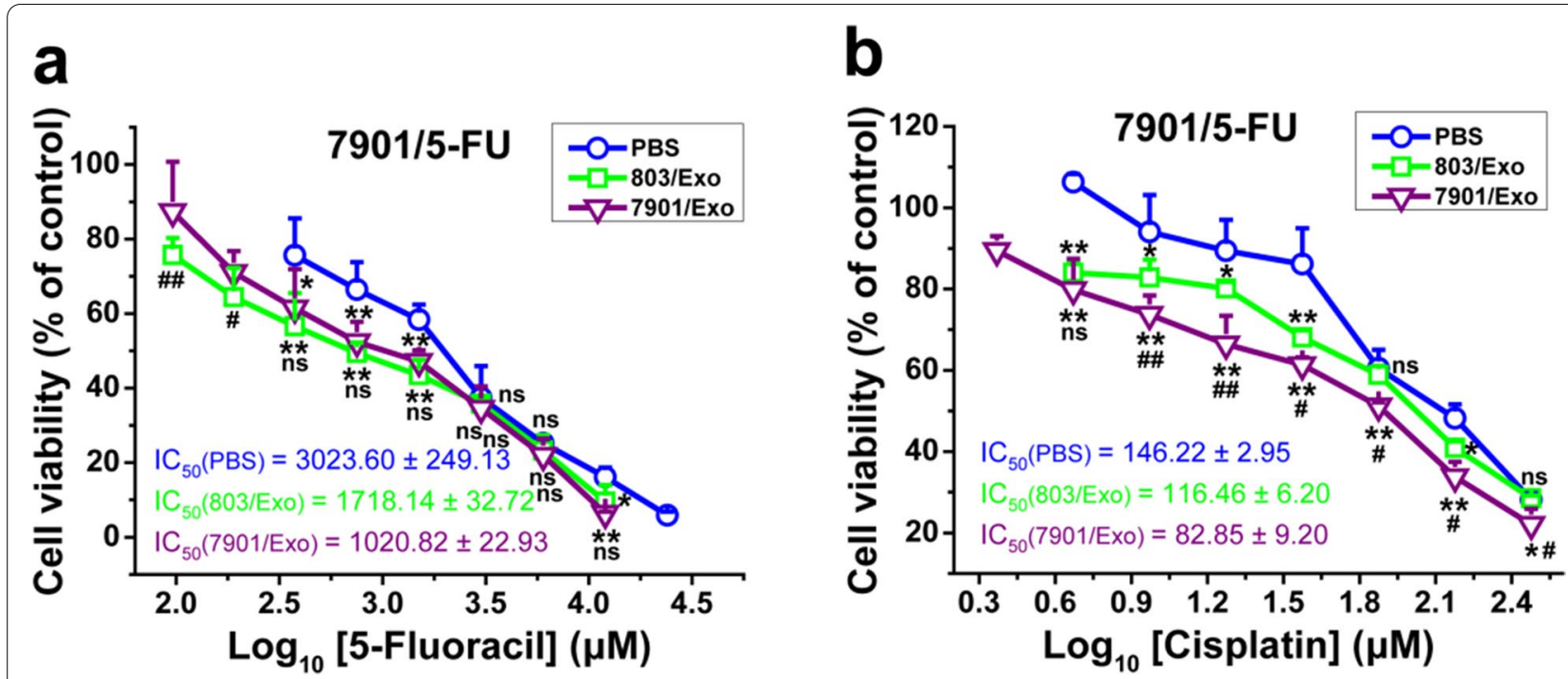

Fig. 3 The exosomes isolated from sensitive GC cells increased drug sensitivity of drug-resistant GC cells. The cell viability of SGC-7901/5-FU cells after treated with 5-FU (a) or CDDP (b) with or without the exosomes isolated from SGC-7901 or MGC-803 cells for 48 or $24 \mathrm{~h}$, respectively. Cell viability was determined by MTT assay. Cells treated with vehicle serve as a blank control. Abbreviations: Exo, exosomes. All experiments were conducted in quintuplicates and data were expressed as the mean $\pm \mathrm{SD}(n=5)$. Statistical significances were determined using one-way ANOVA followed by Dunnett's test. ${ }^{*} P<0.05,{ }^{* *} P<0.01$, compared with the PBS control group, ${ }_{i} P<0.05,{ }^{\# \#} P<0.01$, compared with the 803/Exo group; ns, no significance $(P>0.05)$, compared with the PBS control or 803/Exo groups

\section{The SGC-7901/5-FU recipient cells absorbed exosomes from sensitive $\mathrm{GC}$ cells}

In order to visualize the absorption of exosomes, we labeled SGC-7901-secreted exosomes with PKH26, a red fluorescent tracer. After we incubated labeled exosomes with SGC-7901/5-FU cells, we observed strong red fluorescence in the cytoplasm of recipient cells and the labeled exosomes gathered around the nucleus in dots or clots under a confocal fluorescence microscope (Fig. 4a), which showed that the exosomes secreted by SGC-7901 were successfully taken up by SGC-7901/5-FU recipient cells. To visualize exosome transfer, MGC-803 cells or MGC-803-pLVX stable cells were replated in the upper chamber of a coculture system with $0.4 \mu \mathrm{m}$ pores, which prevents direct contact between the cells and allow the transmission of exosomes but not cells. After $48 \mathrm{~h}$ of coculture, we also observed green fluorescence appeared in the cytoplasm of SGC-7901/5-FU cells, although the numbers of green vesicles were relatively weak (Fig. 4b). Also, compared with the group of MGC-803 normal cells, about $16 \%$ green fluorescence signal were detected by FACS analysis in MGC-803-pLVX stable cells group (Fig. 4c), which demonstrated that the exosomes labeled with green fluorescence and exosomal contents might be directly transferred from MGC-803 donor cells to SGC7901/5-FU recipient cells. All together, these results indicated that exosomes could shuttle from the sensitive GC cells to the SGC-7901/5-FU resistant GC cells. Since exosomes could be taken up by SGC-7901/5-FU cells, we deduced that the contents of exosomes would also be uptaken by resistant cells.

\section{SGC-7901-secreted exosomal miR-107 reversed drug} resistance of SGC-7901/5-FU cells by targeting HMGA2

We also tested the expression levels of miR-107 and HMGA2 mRNA in the SGC-7901, MGC-803 sensitive and SGC-7901/5-FU resistant cells and exosomes, and found that the expression levels of miR-107 in MGC-803 cells and exosomes were lower than that of SGC-7901 cells and exosomes. Moreover, the miR-107 levels in SGC-7901/5-FU resistant cells and exosomes were significantly lower than those of SGC-7901 and MGC-803 cells and exosomes (Fig. 5a and c). Simultaneously, the mRNA level of HMGA2 in MGC-803 was higher than that of SGC-7901 cells, and in SGC-7901/5-FU resistant cells, the HMGA2 mRNA level was significantly higher than that of SGC-7901 and MGC-803 cells (Fig. 5b). These results indicated that the expression of miR-107 in drugresistant cells and exosomes were significantly different compared to sensitive cells and exosomes, and the target molecules of miR-107 may be HMGA2.

In order to study the effect of miR-107 on drug sensitivity of resistant GC cells, we transfected SGC-7901/5-FU and SGC-7901/CDDP cells with miR-107 mimic/NC and treated with 5 -FU or CDDP. The results showed that miR-107 overexpression increased the sensitivity 


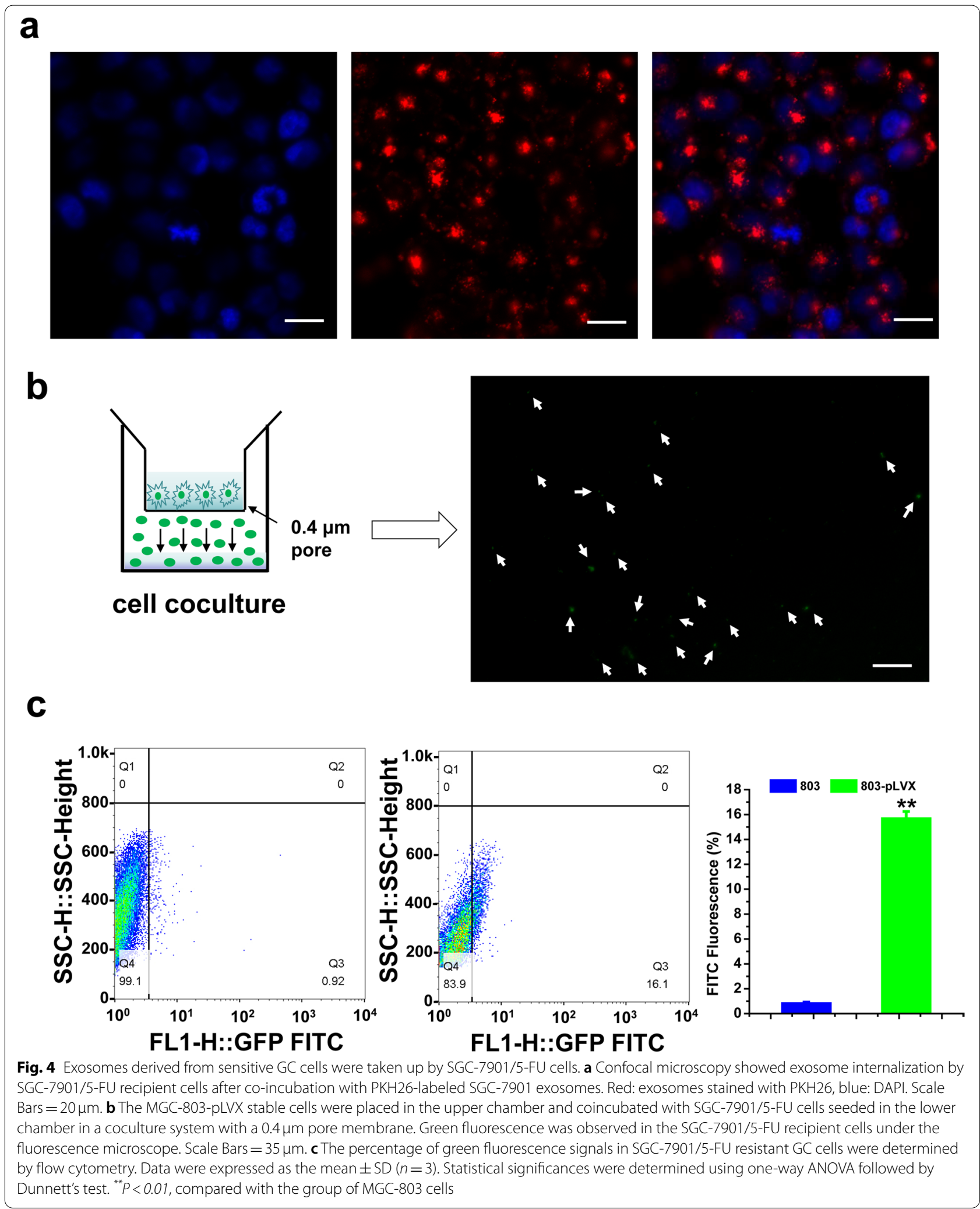



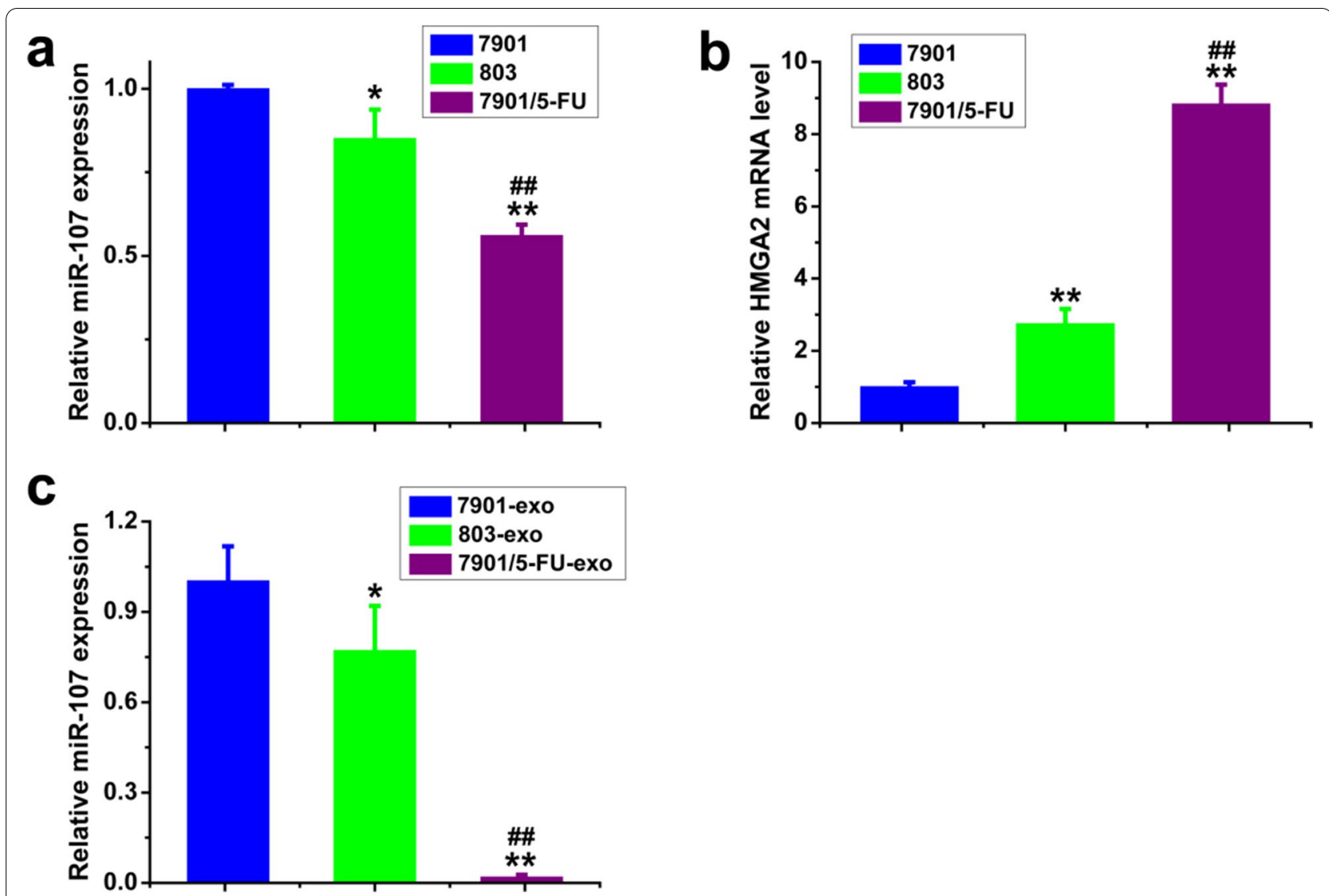

Fig. 5 The expression levels of miR-107 and HMGA2 mRNA in SGC-7901, MGC-803 and SGC-7901/5-FU cells and exosomes were detected by qPCR. the expression levels of miR-107 (a) and HMGA2 mRNA (b) in SGC-7901, MGC-803 sensitive and SGC-7901/5-FU resistant cells; the expression levels of miR-107 (c) in SGC-7901, MGC-803 sensitive and SGC-7901/5-FU resistant exosomes. mRNA and miRNA levels were determined by qPCR using GAPDH and U6 as the internal control, respectively. Data were expressed as the mean $\pm S D(n=3)$. Statistical significances were determined using one-way ANOVA followed by Dunnett's test. ${ }^{*} P<0.05,{ }^{* *} P<0.01$, compared with SGC-7901 cells/exosomes; ${ }^{\# \# ~} P<0.01$, compared with MGC-803 cells/ exosomes

of SGC-7901/5-FU and SGC-7901/CDDP cells to 5-FU and CDDP (Additional file 1: Fig. S2). It is of note that SGC-7901/CDDP cell lines were resistant to CDDP and also cross-resistant to 5-FU compared with SGC-7901 sensitive cells (Additional file 1: Fig. S2). The $\mathrm{IC}_{50}$ values in the SGC-7901/5-FU cells decreased from $3668.70 \mu \mathrm{M}$ to $1484.38 \mu \mathrm{M}$ for 5 -FU and from $131.52 \mu \mathrm{M}$ to $80.68 \mu \mathrm{M}$ for CDDP, respectively. The $\mathrm{IC}_{50}$ values in the SGC-7901/ CDDP resistant cells decreased from $2718.31 \mu \mathrm{M}$ to $1606.48 \mu \mathrm{M}$ for 5 -FU and from $236.51 \mu \mathrm{M}$ to $89.76 \mu \mathrm{M}$ for CDDP, respectively. Thus, we found that miR-107 from sensitive cells exosome may reverse chemotherapy drugs resistance of SGC-7901/5-FU cells.

\section{HMGA2 was the target gene of miR-107}

According to the Targetscan software analysis, HMGA2 3'-UTR had a pseudo binding site with miR107 (Fig. 6a). To verify this prediction, a luciferase reporter assay was performed. The results showed that the expression level of miR-107 in $293 \mathrm{~T}$ cells transfected with miR-107 mimic was 5.38 times higher than that transfected with miR-NC (Additional file 1: Fig. S3a). The overexpression of miR-107 reduced the luciferase activity in $293 \mathrm{~T}$ cells cotransfected with the pEZX-MT05-MT reporter plasmid containing wild type HMGA2 3'-UTR. However, there was no significant change of the luciferase activity in $293 \mathrm{~T}$ cells cotransfected with the pEZX-MT05-MUT reporter plasmid containing mutant HMGA2 3'-UTR (Fig. 6b). What's more, we found that the protein expression level and mRNA level of HMGA2 were significantly up-regulated treated with miR-107 inhibitor (Figs. 9c,f and 10a). Also, we found that miR-107 overexpression downregulated the expression of HMGA2 (Additional file 1: Fig. S4). All together, these results demonstrated that HMGA2 was the target molecular of miR-107. 
a

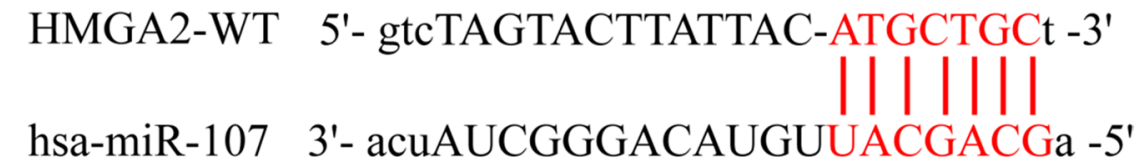

HMGA2-MUT 5'- gtcTAGTACTTATTAC-TACGACGt -3'

b

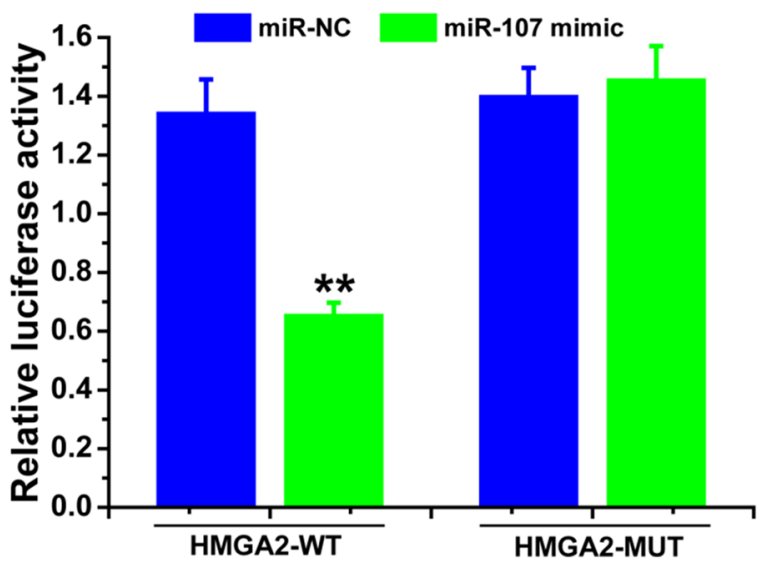

Fig. 6 Downstream target molecular of miR-107 was HMGA2. a Predicted binding sites of miR-107 in HMGA2 3'-UTR. b Plasmid vectors of human HMGA2 3'-UTR or its mutation were transfected into 293T cells together with miR-107 mimic or NC. Data were expressed as fold change of the luciferase activity over the control from the NC group (mean $\pm S D, n=3$ ). Statistical significances were determined using one-way ANOVA followed by Dunnett's test. ${ }^{* *} P<0.01$, compared with respective controls

The drug resistance of SGC-7901/5-FU cells was reversed via exosomes transfer of SGC-7901 cells

In order to verified that the improved drug sensitivity of SGC-7901/5-FU cells was indeed mediated by sensitive cells-secreted exosomes, we treated SGC-7901 cells with the GW4869, which inhibits the synthesis and secretion of exosomes, and then treated SGC-7901/5-FU cells together with exosomes and 5-FU or CDDP. We found that the SGC-7901-secreted exosomes, which were treated with GW4869, could no longer increased the drug sensitivity of SGC-7901/5-FU cells to 5-FU and CDDP compared with SGC-7901-secreted exosomes, which were treated with DMSO (Fig. 7). These results showed that the drug resistance of SGC-7901/5-FU cells was reversed by exosomes transfer of SGC-7901 cells.

\section{Exosomal miR-107 secreted by SGC-7901 reversed drug resistance of SGC-7901/5-FU cells through targeting HMGA2}

In order to evaluated whether exosomal miR-107 increased drug sensitivity in SGC7901/5-FU cells by targeting HMGA2, we transfected SGC-7901 cells with a miRNA-107 inhibitor (107 i) together with siRNA specific for HMGA2 (107i+siHMGA2) or negative control miRNA-107 inhibitor/siHMGA2 (NC). The expression levels of miR-107 and HMGA2 mRNA in SGC-7901 cells transfected with miR-107 inhibitor or siHMGA2 were 22 and $32 \%$ of those transfected with $\mathrm{NC}$, respectively (Additional file 1: Fig. S3b and c). As shown in Fig. 8, SGC-7901 (NC) exosomes dramatically increased the drug sensitivity of SGC-7901/5-FU cells to 5-FU and CDDP, whereas no significant difference was seen for miR-107 silenced SGC-7901 (107 i) exosomes. What's more, the exosomes isolated from SGC-7901 (107 i + siHMGA2) cells also reversed the resistance of SGC-7901/5-FU cells to 5-FU and CDDP. Taken together, these results suggested that the exosomes secreted by miR-107 knockdown sensitive GC cells no longer increased the sensitivity of SGC7901/5-FU cells to chemotherapy drugs 5-FU and CDDP, and reversed drug resistance can be achieved by exosomal transfer of miR-107 possibly through inhibiting HMGA2 expression in SGC-7901/5-FU cells. 

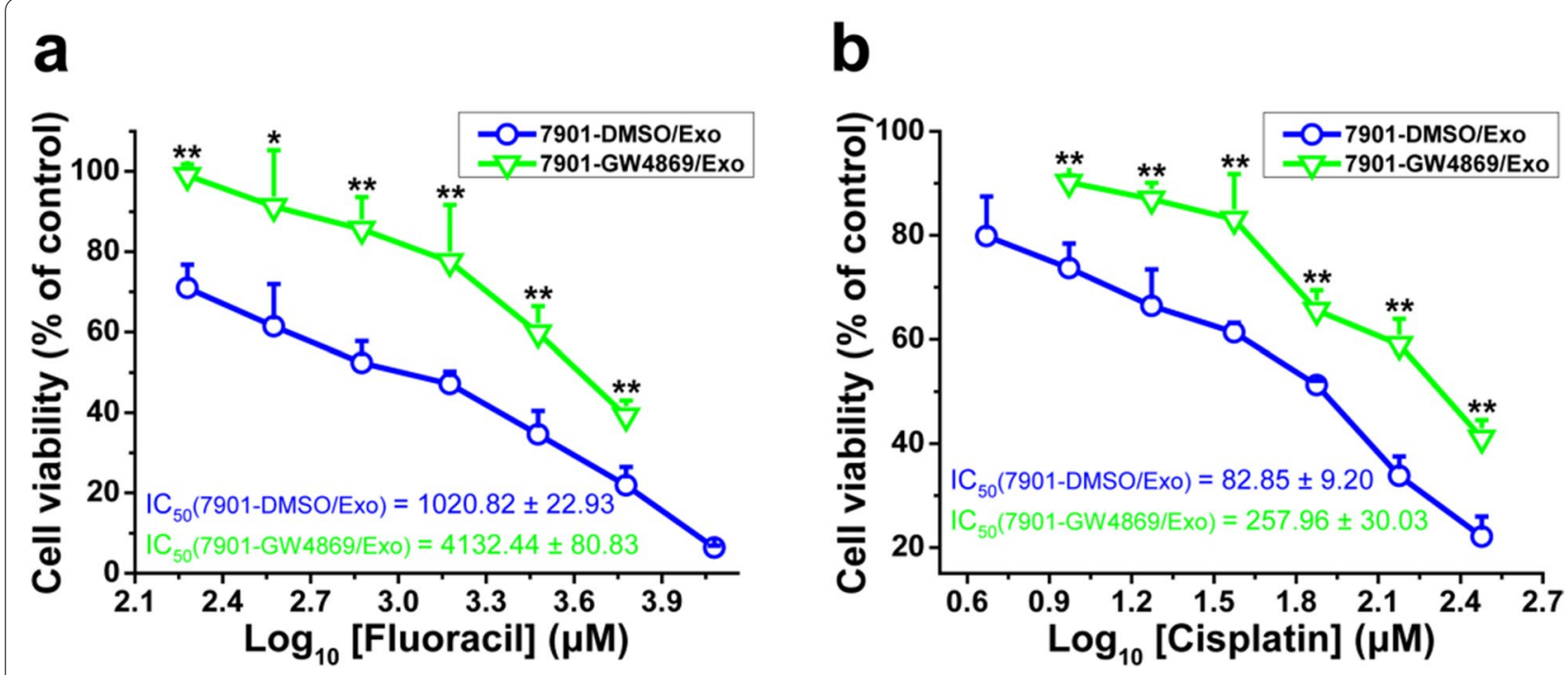

Fig. 7 Exosomes transfer increased drug sensitivity of SGC-7901/5-FU cells. The cell viability of SGC-7901/5-FU cells after treated with 5-FU (a) or CDDP (b) combined with exosomes extracted from SGC-7901 cells (with or without the exosome inhibitor GW4869 treatment) for 48 or $24 \mathrm{~h}$, respectively. Cell viability was determined by MTT assay. Cells treated with vehicle serve as a blank control. Abbreviations: Exo, exosomes. All experiments were conducted in quintuplicates and data were expressed as the mean \pm SD $(n=5)$. Statistical significances were determined using one-way ANOVA followed by Dunnett's test. ${ }^{*} P<0.05,{ }^{* *} P<0.01$, compared with the DMSO/Exo control group
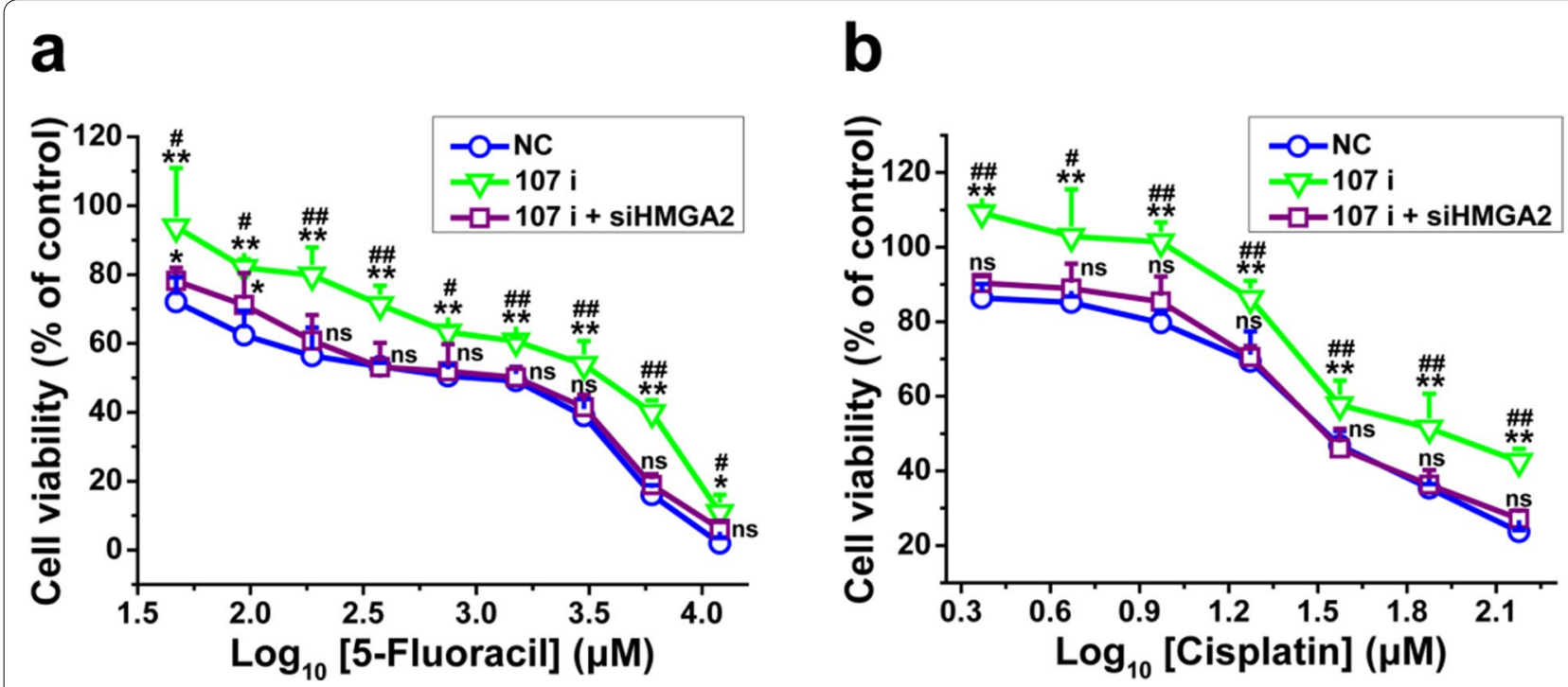

Fig. 8 SGC-7901-secreted exosomal miR-107 reversed drug resistance of SGC-7901/5-FU cells by inhibiting HMGA2. The SGC-7901 cells were transfected with miRNA-107 inhibitor, co-transfection with miRNA-107 inhibitor and siRNA traget for HMGA2 and miRNA-107 inhibitor/siHMGA2 negative control for $24 \mathrm{~h}$, and the cell viability of SGC-7901/5-FU cells after treated with different concentrations of 5-FU (a) or CDDP (b) combined with exosomes extracted from SGC-7901 (NC, 107 i, 107 i siHMGA2) cells for 48 or $24 \mathrm{~h}$, respectively. Cell viability was determined by MTT assay. Cells treated with vehicle serve as a blank control. Abbreviations: Exo, exosomes. All experiments were conducted in quintuplicates and data were expressed as the mean $\pm \mathrm{SD}(n=5)$. Statistical significances were determined using one-way ANOVA followed by Dunnett's test. ${ }^{*} P<0.05$, ${ }^{* *} P<0.01$, compared with negative control transfection group; ${ }^{*} P<0.05,{ }^{\# \#} P<0.01$, compared with miRNA-107 inhibitor/siHMGA2 co-transfection group; ns, no significance $(P>0.05)$, compared with the negative control transfection and miRNA-107 inhibitor/siHMGA2 co-transfection groups 
Exosomal miR-107 reversed drug resistance of SGC-7901/5-FU recipient cells through HMGA2/mTOR/ P-gp pathway

We then sought to reveal the underlying molecular mechanism of how exosomal miR-107/HMGA2 axis reversed drug resistance of SGC-7901/5-FU cells. In our experiments, we found that the expression of HMGA2 and P-gp were significantly higher and mTOR was overactivated in SGC-7901/5-FU cells compared with the SGC-7901 and MGC-803 cells (Fig. 9a and d). As shown in Fig. 9b,c,e,f and Fig. 10, the protein expression levels of HMGA2, p-mTOR (Ser 2448), P-gp and the mRNA level of HMGA2 in SGC-7901/5-FU cells were significantly down-regulated by SGC7901 (transfected with NC or with $107 \mathrm{i}+$ siHMGA2)-secreted exosomes treatment. Conversely, inhibition of exosome secretion or miR-107 knockdown in SGC-7901 exosomes increased the protein expression levels of HMGA2 p-mTOR, P-gp and the mRNA level of HMGA2 compared with control. Also, we found that miR-107 overexpression downregulated the expression of HMGA2, p-mTOR and P-gp, which indicated that miR-107 overexpression inhibited the activation of HMGA2/mTOR/P-gp pathway (Additional file 1: Fig. S4). In all, these results demonstrated that the increased sensitivity of cells to chemotherapeutic drugs by exosomal miR-107 was mediated by inhibiting the expression of HMGA2 and the activation of HMGA2/ mTOR/P-gp axis.

To further study the role of HMGA2/mTOR pathway on resistant GC cells to chemotherapy drugs, we transfected SGC-7901/5-FU and SGC-7901/CDDP cells with siHMGA2 with or without pEX-HMGA2WT or pEX-HMGA2-MUT43. The expression level of HMGA2 in SGC-7901/5-FU cells transfected with siRNA for HMGA2 was only $26 \%$ of control (Additional file 1: Fig. S5a), and the expression level of HMGA2 in SGC-7901/5-FU cells transfected with HMGA2-WT was 2.68 times of control. The HMGA2 deletion mutant expressed by pEX-HMGA2-MUT43 was too small to detect (Additional file 1: Fig. S5b). The HMGA2 mutant

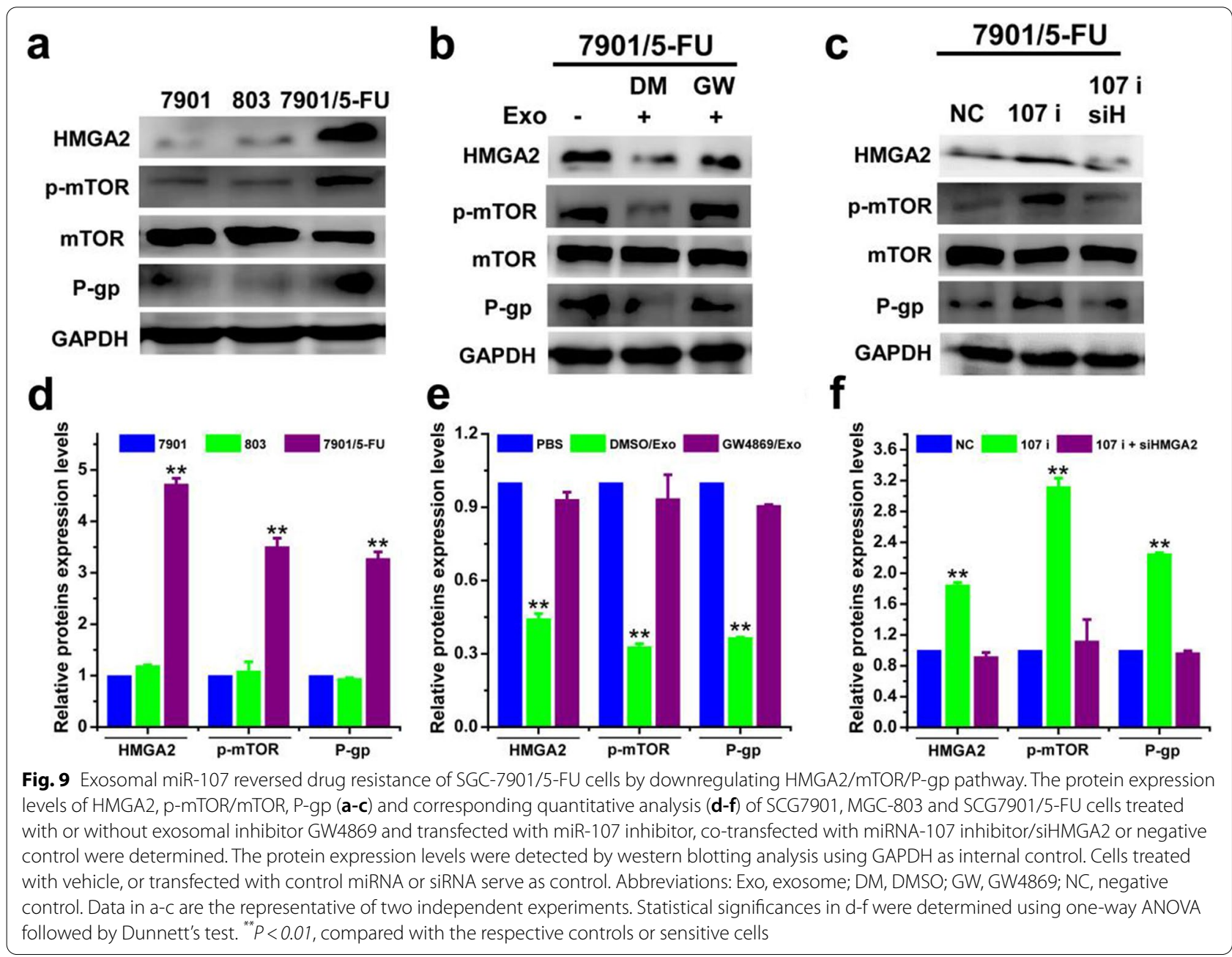




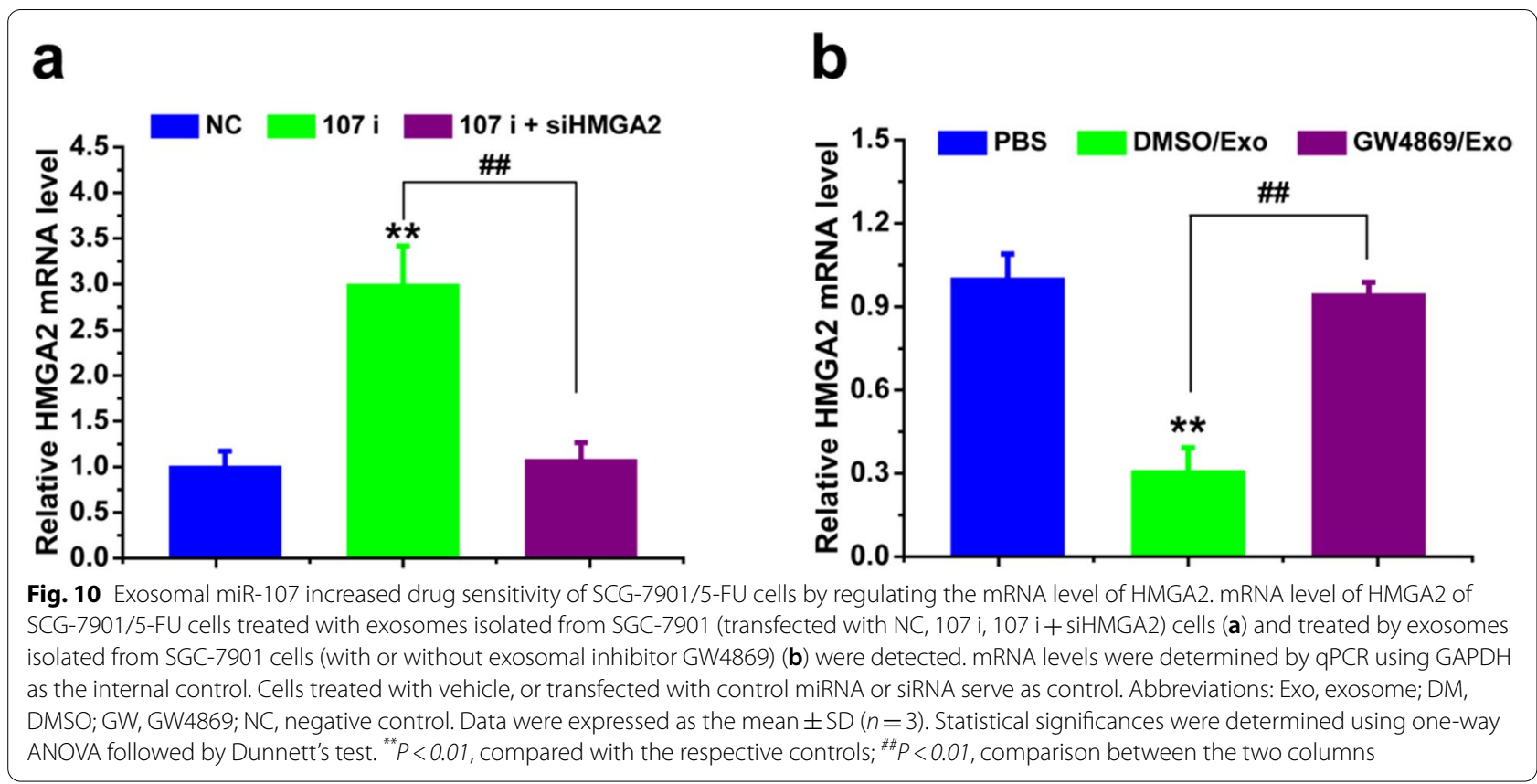

overexpression with HMGA2 knockdown increased 5-FU and CDDP sensitivity of SGC-7901/5-FU and SGC7901/CDDP cells. However, HMGA2-WT overexpression with HMGA2 knockdown could not increase the sensitivity of resistant cells (Fig. 11a-b). Meanwhile, we found that inhibiting mTOR activity by rapamycin also could increase sensitivity of SGC-7901/5-FU and SGC7901/CDDP cells (Fig. 11c-d). Altogether, these results demonstrated that inhibiting HMGA2/mTOR pathway improved sensitivity of resistant GC cells to chemotherapy drugs, and HMGA2/mTOR pathway plays important roles in drug resistance.

\section{Discussion}

Chemotherapy resistance seriously affects the treatment of GC. In this study, we showed that exosomes derived from sensitive GC cells could increase the sensitivity of resistant GC cells to chemotherapeutic drugs. The reversal effects were mediated by exosomal miR-107 through targeting HMGA2 and regulating the activation of HMGA2/mTOR/P-gp pathway (Fig. 12).

Exosomes are a subgroup of extracellular vesicles, which serve as a carrier of cell contents (proteins, nucleic acid, lipids). In the past few years, it has been revealed that exosomes play an important role in mediating communication between cells, and its contents also play a certain role in mediating cancer cells resistance [23]. There are four ways for exosomes to mediate cell communication, which including 1 , exosomes recognize the surface receptors by ligand-receptor binding; 2, exosomes directly fuse with target cells to achieve receptor transfer; 3, exosomes fuse with target cells and release content proteins; 4, exosomes transfer genetic information (mRNA, non-coding RNA, DNA) to target cells [24]. The interaction of exosomes and targets cells was a crucial step to induce biological effect. Thus we also used a variety of methods, such as PKH26 staining, transwell and flow cytometry, to prove that exosomes secreted by sensitive GC cells were uptaken by resistant GC cells. And the inhibitor GW4689, which inhibits the synthesis and release of exosomes, was used to prove that the exosomes from sensitive $\mathrm{GC}$ cells could reverse drug resistance of SGC-7901/5-FU cells.

There have been many reports showing that the regulatory role of exosomal miRNA could regulate chemotherapy resistance of cancer cells. For example, exosomal microRNA-32-5p induces multidrug resistance in hepatocellular carcinoma [25], macrophages derived exosomal miR-223 induced a chemoresistant phenotype of epithelial ovarian cancer cells through exosomal miR223/PTEN-PI3K/AKT signaling pathway [26]. In GC cells, the MGC-803 sensitive cells became resistant to paclitaxel because exosomal miRNA-155-5p inhibited the expressions of GATA3 and TP53INP1 [27]. MGC803/ CDDP-derived exosomes enhance CDDP resistance of MGC803 recipient cells via exosomal delivery of miR500a-3p [28]. Although a variety of exosomal miRNAs have been reported to regulate chemotherapeutics sensitivity of cancer cells, the effect of exosomal miRNA-107 on the drug resistance of GC cells has not been reported. 


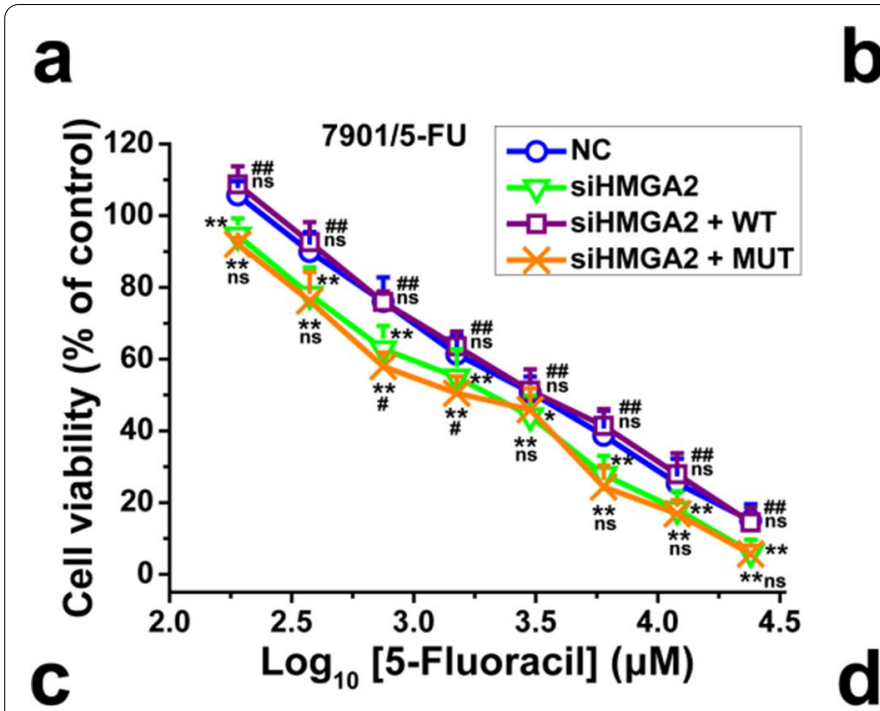

b
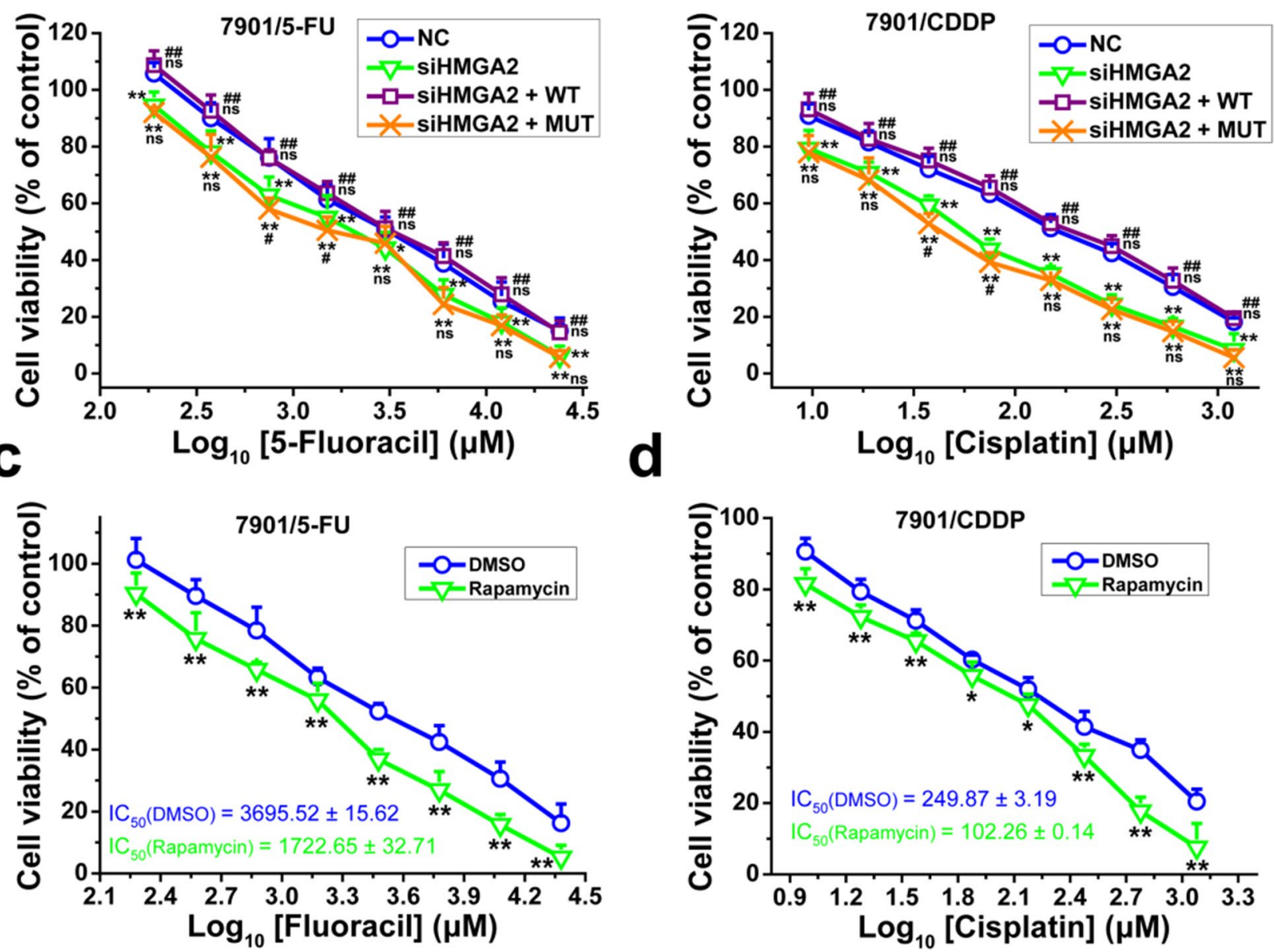

Fig. 11 Inhibition of HMGA2/mTOR pathway increased drug sensitivity of SGC-7901/5-FU and SGC-7901/CDDP cells. The cell viability of SGC-7901/5-FU (a and $\mathbf{c}$ ) and SGC-7901/CDDP (b and $\mathbf{d}$ ) cells was determined after cells were transfected with siHMGA2/NC together with pEX-HMGA2-WT/MUT43 plasmid vectors (a and $\mathbf{b})$ or treated with or without rapamycin (10 $\mu \mathrm{M})(\mathbf{c}$ and $\mathbf{d})$ and then treated with 5-FU (a and $\mathbf{c})$ or CDDP (b and $\mathbf{d}$ ) for 48 or $24 \mathrm{~h}$, respectively. Cell viability was determined by MTT assay. Cells treated with vehicle serve as a blank control. All experiments were conducted in quintuplicates and data were expressed as the mean $\pm \mathrm{SD}(n=5)$. Statistical significances were determined using one-way ANOVA followed by Dunnett's test. ${ }^{*} P<0.05,{ }^{* *} P<0.01$, compared with negative control transfection/DMSO group; ${ }^{\#} P<0.05$, ${ }^{\#} P<0.01$, compared with siHMGA2 transfection group; ns, no significance $(P>0.05)$, compared with the negative control transfection and siHMGA2 transfection groups

In our study, we first found that exosomal miR-107 from sensitive GC cells (SGC-7901 and MGC-803 cells) could increase the sensitivity of two resistant $\mathrm{GC}$ cell lines SGC-7901/5FU and SGC-7901/CDDP to chemotherapy drugs 5-FU and CDDP. Results from multiple sensitive and resistant GC cell lines support the notion that exosomes isolated from sensitive GC cells could reverse the drug resistance. Thus, exosomal miR-107 might provide a new target for improving the drug sensitivity of GC patients.

Some reports demonstrated that HMGA2 also had a certain effect on the chemotherapeutics sensitivity of cancer cells. HMGA2 regulated the progression and the sensitivity of acute myeloid leukemia to doxorubicin by activating the $\mathrm{Wnt} / \beta$-catenin signaling pathway [29]. miR-26a could regulate the resistance of human non-small cell lung cancer to cisplatin by regulating the expression of HMGA2 through the E2F1-Akt pathway [30]. In GC cells, HMGA2 might be a potential target molecule of miR-33b-5p, and up-regulation of miR-33b-5p reduced the expression of HMGA2, inhibited the growth of GC cells, and improved the sensitivity of GC cells to chemotherapy drugs [31]. Some literature suggested that HMGA2 might be the target of 


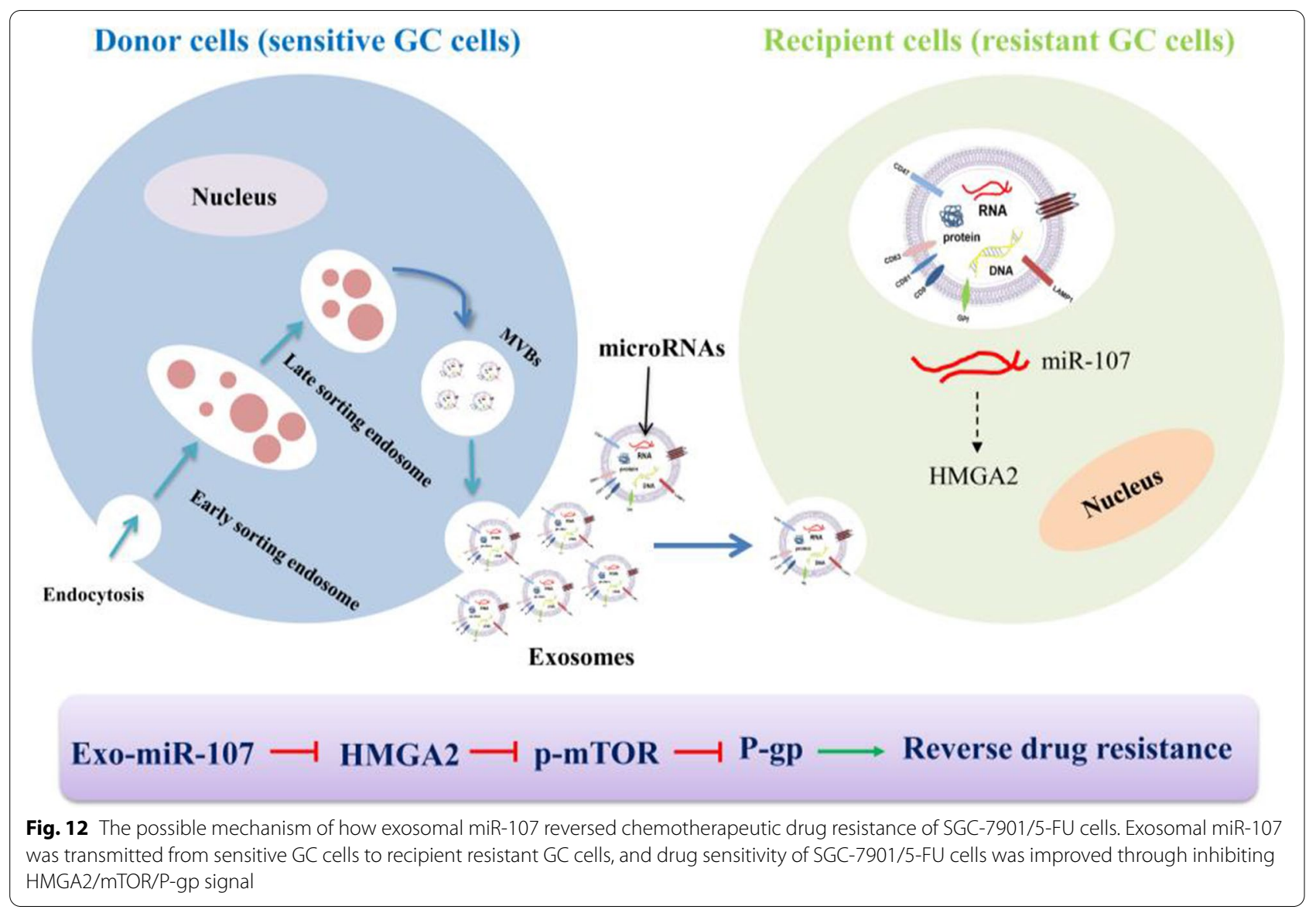

miRNA-107, and miRNA-107 could inhibit the proliferation of liver cancer cells by targeting HMGA2 mRNA 3'-UTR [32]. LncRNA LINC00152 promoted the progression of glioblastoma by targeting miR-107 and regulating the expression of HMGA2 [33]. Consistently, in our study, we verified that HMGA2 was the target molecular of exosomal miR-107 using luciferase reporter assay, western blotting and qPCR assay. And exosomal miR-107 improved the sensitivity of resistant GC cells to chemotherapy drugs by targeting HMGA2.

Some studies indicated that HMGA2 could regulate the downstream mTOR signal [34]. Tan $\mathrm{L}$ et al. reported that aberrant expression of HMGA2 induced acute myeloid leukemia cell proliferation through the PI3K/Akt/mTOR signaling pathway [35]. miR-590 suppressed proliferation and induced apoptosis of pancreatic cancer by targeting HMGA2 and inhibiting the phosphorylation of mTOR [36]. It is well known that a major mechanism of resistance in cancer cells is the overexpression of P-gp, also known as multidrug resistance protein 1 (MDR1) or ABCB1, which belong to ATP-binding cassette (ABC) transporters and could efflux the chemotherapeutic agents out of cells [37]. Some studies showed that mTOR signal could regulate the expression of P-gp and affect the drug resistance of cancer cells [38-40]. In this study, we also found that the expression of P-gp could be regulated by mTOR signal, and exosomal miR-107 regulated the expression of P-gp mediated by HMGA2 and the activity of mTOR signal.

\section{Conclusion}

In summary, our study reveals that exosome-transmitted miR-107 increased the sensitivity of resistant GC cells to the chemotherapeutic drugs. Mechanistically, the expression of target molecule HMGA2 and the activity of HMGA2/mTOR/P-gp signal were downregulated by horizontal transfer of exosomal miR-107. Therefore, we propose that exosomal miR-107 might be used as a potential diagnostic biomarker and therapeutic target for gastric cancers.

\section{Abbreviations}

GC: Gastric cancer; TEM: Transmission electron microscopy; DLS: Dynamic light scattering; RT-qPCR: Real-time quantitative PCR; aa:: amino acid; CDDP: cisplatin; HMGA2: High mobility group A2; P-gp: P-glycoprotein; Gluc: Gaussia Iuciferase; SeAP: secreted alkaline phosphatase; MDR1: Multidrug resistance protein 1; ABC: ATP-binding cassette; NC: Negative control. 


\section{Supplementary Information}

The online version contains supplementary material available at https://doi. org/10.1186/s12885-021-09020-y.

Additional file 1: Figure S1. The exosomes isolated from SGC-7901 cells increased drug sensitivity of SGC-7901/CDDP cells. The cell viability of SGC-7901/CDDP cells was determined after cells were treated with CDDP with or without the exosomes isolated from SGC-7901 for $24 \mathrm{~h}$. Cell viability was determined by MTT assay. Cells treated with vehicle serve as a blank control. Abbreviations: Exo, exosomes. All experiments were conducted in quintuplicates and data were expressed as the mean \pm SD $(n=5)$. Statistical significances were determined using one-way ANOVA followed by Dunnett's test. ${ }^{* *} P<0.01$, compared with the PBS control group. Figure S2. miR-107 overexpression increased drug sensitivity of SGC-7901/5-FU and SGC-7901/CDDP cells. The cell viability of SGC7901/5-FU ( $a$ and b) and SGC-7901/CDDP (c and d) cells was determined after cells were transfected with miR-107 mimic or NC and treated with 5-FU ( $a$ and $c$ ) or CDDP ( $b$ and d) for 48 or $24 \mathrm{~h}$, respectively. Cell viability was determined by MTT assay. Cells treated with vehicle serve as a blank control. All experiments were conducted in quintuplicates and data were expressed as the mean $\pm S D(n=5)$. Statistical significances were determined using one-way ANOVA followed by Dunnett's test. ${ }^{* *} P<0.01$, compared with the control group. Figure S3. The expression levels of miR-107 and HMGA2 mRNA in 293T and SGC-7901 cells were detected. a The expression level of miR-107 in 293T cells transfected with miR-107 mimic and miR-NC. b The expression level of miR-107 in SGC-7901 cells transfected with miR-107 inhibitor and miR-NC. c The mRNA level of HMGA2 in SGC-7901 cells transfected with siHMGA2 and NC. mRNA and miRNA levels were determined by qPCR using GAPDH and $U 6$ as the internal control, respectively. Data were expressed as the mean $\pm S D(n=3)$. Statistical significances were determined using one-way ANOVA followed by Dunnett's test. ${ }^{* *} P<0.01$, compared with the respective controls. Figure S4. miR-107 overexpression downregulated HMGA2/mTOR/P-gp pathway. The protein expression levels of HMGA2, p-mTOR/mTOR, P-gp (a) and corresponding quantitative analysis (b) in SCG7901/5-FU cells transfected with miR-107 mimic or NC were determined. The protein expression levels were detected by western blotting analysis using GAPDH as internal control. Cells transfected with control miRNA serve as control. Statistical significances in b were determined using one-way ANOVA followed by Dunnett's test. ${ }^{* *} P<0.01$, compared with the control. Figure $\mathbf{S 5}$. The expression level of HMGA2 in SGC-7901/5-FU cells. a The expression level of HMGA2 in SGC-7901/5-FU cells transfected with siRNA target for HMGA2. b The expression level of HMGA2 in SGC-7901/5-FU cells transfected with HMGA2-MUT43, HMGA2-WT vectors. The protein expression levels were detected by western blotting analysis using GAPDH as internal control. Abbreviations: NC: negative control; H-MUT, pEX-HMGA2-MUT43; H-WT, pEX-HMGA2-WT. The data represents the density of bands.

\section{Additional file 2.}

Additional file 3.

\section{Acknowledgements}

Not applicable.

\section{Authors' contributions}

$L J$ and WHR designed the research studies. $L, Y Z, L H G$ and $C Y L$ performed the research. $L J$ interpreted the data. $L J$ and WHR cowrote the manuscript. PW helped revision of the manuscript. All authors read and approved the final manuscript.

\section{Funding}

This work was supported in part by the grants from the Colleges and Universities Key Scientific Research Project Plan Basic Research Special of Henan Province (Grant number 19zx009), Science and Technology Project for Tackling Key Problems of Henan Province (Grant number 212102310639), and Doctoral Research Startup Fund of Henan University of Traditional Chinese Medicine (Grant number RSBSJJ2019-26).

\section{Availability of data and materials}

All data generated or analysed during this study are included in this published article and its supplementary information files.

\section{Declarations}

Ethics approval and consent to participate

Not applicable.

\section{Consent for publication}

Not applicable.

\section{Competing interests}

The authors declare that they have no competing interests.

\section{Author details}

${ }^{1}$ Henan University of Chinese Medicine, 156 Jinshui East Road, Zhengzhou 450046, China. ${ }^{2}$ School of Life and Health Sciences, The Chinese University of Hong Kong (Shenzhen), 2001 Longxiang Ave, Shenzhen 518172, China. ${ }^{3}$ Department of Clinical Laboratory, The First Affiliated Hospital of Henan University of Chinese Medicine, 19 Renmin Road, Zhengzhou 450000, China.

Received: 20 May 2021 Accepted: 15 November 2021

Published online: 02 December 2021

\section{References}

1. Arbyn M, Weiderpass E, Bruni L, de Sanjosé S, Saraiya M, Ferlay J, et al. Estimates of incidence and mortality of cervical cancer in 2018: a worldwide analysis. Lancet Glob Health. 2020;8(2):e191-203. https://doi.org/10.1016/ S2214-109X(19)30482-6.

2. Smyth EC, Nilsson M, Grabsch HI, van Grieken NC, Lordick F. Gastric cancer. Lancet. 2020;396(10251):635-48. https://doi.org/10.1016/S01406736(20)31288-5.

3. Liu X, Lu Y, Xu YC, Hou SZ, Huang JL, Wang B, et al. Exosomal transfer of miR-501 confers doxorubicin resistance and tumorigenesis via targeting of BLID in gastric cancer. Cancer Lett. 2019;459:122-34. https://doi.org/10. 1016/j.canlet.2019.05.035

4. He ZY, Li Z, Zhang X, Yin K, Wang WZ, Xu ZP, et al. MiR-422a regulates cellular metabolism and malignancy by targeting pyruvate dehydrogenase kinase 2 in gastric cancer. Cell Death Dis. 2018;9:505. https://doi.org/10. 1038/s41419-018-0564-3.

5. Pastan I, Gottesman MM. Multidrug resistance. Annu Rev Med. 1991;42:277-86 Https://doi.org/10.1146/annurev.me.42.020191.001425.

6. Mowla M, Hashemi A. Functional roles of exosomal miRNAs in multi-drug resistance in cancer chemotherapeutics. Exp Mol Pathol. 2021;118:104592. https://doi.org/10.1016/j.yexmp.2020.104592.

7. Santos P, Almeida F. Role of exosomal miRNAs and the tumor microenvironment in drug resistance. Cells. 2020;9(6):1450. https://doi.org/10.3390/ cells 9061450 .

8. Zhang Y, Bi JY, Huang JY, Tang YN, Du SY, Li PY, et al. Exosome: a review of its classification, isolation techniques, storage, diagnostic and targeted therapy applications. Int J Nanomedicine. 2020;15:6917-34. https://doi. org/10.2147/IJN.S264498.

9. Mashouri L, Yousefi H, Aref AR, Ahadi AM, Molaei F, Alahari SK. Exosomes: composition, biogenesis, and mechanisms in cancer metastasis and drug resistance. Mol Cancer. 2019;18(1):75. https://doi.org/10.1186/ s12943-019-0991-5.

10. Liu T, Zhang X, Du LT, Wang YS, Liu XM, Tian H, et al. Exosome-transmitted miR-128-3p increase chemosensitivity of oxaliplatin-resistant colorectal cancer. Mol Cancer. 2019;18(1):43. https://doi.org/10.1186/ s12943-019-0981-7.

11. Ma YZ, Yuwen DL, Chen JW, Zheng BF, Gao J, Fan MM, et al. Exosomal transfer of cisplatin-induced miR-425-3p confers cisplatin resistance in NSCLC through activating autophagy. Int J Nanomedicine. 2019;14:812132. https://doi.org/10.2147/IJN.S221383.

12. Liang Y, Zhu DX, Hou LD, Wang Y, Huang X, Zhou C, et al. MiR-107 confers chemoresistance to colorectal cancer by targeting calcium-binding 
protein 39. Br J Cancer. 2020;122(5):705-14. https://doi.org/10.1038/ s41416-019-0703-3.

13. Jiao YN, Kong L, Yao YJ, Li SH, Tao ZY, Yan YH, et al. Osthole decreases beta amyloid levels through up-regulation of miR-107 in Alzheimer's disease. Neuropharmacology. 2016;108:332-44. https://doi.org/10.1016/j.neuro pharm.2016.04.046.

14. Lin SS, Yuan LJ, Niu CC, Tu YK, Yang CY, Ueng SWN. Hyperbaric oxygen inhibits the HMGB1/RAGE signaling pathway by upregulating Mir-107 expression in human osteoarthritic chondrocytes. Osteoarthr Cartil. 2019;27(9):1372-81. https://doi.org/10.1016/j.joca.2019.05.011.

15. Lu CJ, Xie ZB, Peng QZ. miRNA-107 enhances chemosensitivity to paclitaxel by targeting antiapoptotic factor BCl-w in non small cell lung cancer. Am J Cancer Res. 2017;7:1863-73.

16. Wang GS, Ma CP, Shi XJ, Guo WC, Niu JX. miR-107 enhances the sensitivity of breast cancer cells to paclitaxel. Open Med (Wars). 2019;14:456-66. https://doi.org/10.1515/med-2019-0049.

17. Inoue T, linuma H, Ogawa E, Inaba T, Fukushima R. Clinicopathological and prognostic significance of microRNA-107 and its relationship to DICER1 mRNA expression in gastric cancer. Oncol Rep. 2012;27(6):175964. https://doi.org/10.3892/or.2012.1709.

18. Vignali R, Marracci S. HMGA genes and proteins in development and evolution. Int J Mol Sci. 2020;21(2):654. https://doi.org/10.3390/ijms210206 54.

19. Wang XH, Huang W, Liu GS, Cai WF, Millard RW, Wang YG, et al. Cardiomyocytes mediate anti-angiogenesis in type 2 diabetic rats through the exosomal transfer of miR-320 into endothelial cells. J Mol Cell Cardiol. 2014;(74):139-50. https://doi.org/10.1016/j.yjmcc.2014.05.001.

20. Li M, Lu Y, Xu YC, Wang JW, Zhang CH, Du Y, et al. Horizontal transfer of exosomal CXCR4 promotes murine hepatocarcinoma cell migration, invasion and lymphangiogenesis. Gene. 2018;676:101-9. https://doi.org/10. 1016/j.gene.2018.07.018.

21. Noro B, Licheri B, Sgarra R, Rustighi A, Tessari MA, Chau K-Y, et al. Molecular dissection of the architectural transcription factor HMGA2. 2003;42(15):4569-77. https://doi.org/10.1021/bi026605k.

22. Jiang $L$, Wang $P$, Sun $Y J$, Wu YJ. Ivermectin reverses the drug resistance in cancer cells through EGFR/ERK/Akt/NF-kB pathway. J Exp Clin Cancer Res. 2019;38(1):265. https://doi.org/10.1186/s13046-019-1251-7.

23. Tan $S M$, Xia LZ, Yi P, Han YQ, Tang L, Pan Q, et al. Exosomal miRNAs in tumor microenvironment. J Exp Clin Cancer Res. 2020;39(1):67. https:// doi.org/10.1186/s13046-020-01570-6.

24. Cao C, Wang B, Tang JN, Zhao JM, Guo JC, Guo QQ, et al. Circulating exosomes repair endothelial cell damage by delivering miR-193a- $5 \mathrm{p}$. $J$ Cell Mol Med. 2021;25(4):2176-89. https://doi.org/10.1111/jcmm.16202.

25. Fu X, Liu MJ, Qu SY, Ma JQ, Zhang YM, Shi TT, et al. Exosomal microRNA$32-5 p$ induces multidrug resistance in hepatocellular carcinoma via the PI3KJAkt pathway. J Exp Clin Cancer Res. 2018;37(1):52. https://doi.org/10. 1186/s13046-018-0677-7.

26. Zhu XL, Shen $\mathrm{HL}$, Yin XM, Yang ML, Wei $\mathrm{H}$, Chen $\mathrm{Q}$, et al. Macrophages derived exosomes deliver miR-223 to epithelial ovarian cancer cells to elicit a chemoresistant phenotype. J Exp Clin Cancer Res. 2019;38(1):81. https://doi.org/10.1186/s13046-019-1095-1.

27. Wang M, Qiu R, Yu SR, Xu XY, Li G, Gu RM, et al. Paclitaxel-resistant gastric cancer MGC-803 cells promote epithelial-to-mesenchymal transition and chemoresistance in paclitaxel-sensitive cells via exosomal delivery of miR-155-5p. Int J Oncol. 2018;54:326-38. https://doi.org/10.3892/ijo.2018. 4601.

28. Lin H, Zhang L, Zhang CH, Liu PP. Exosomal MiR-500a-3p promotes cisplatin resistance and stemness via negatively regulating FBXW7 in gastric cancer. J Cell Mol Med. 2020;24(16):8930-41. https://doi.org/10.1111/ jcmm.15524.

29. Yang S, Gu YL, Wang GJ, Hu QZ, Chen SX, Wang Y, et al. HMGA2 regulates acute myeloid leukemia progression and sensitivity to daunorubicin via Wht/ß-catenin signaling. Int J Mol Med. 2019;44(2):427-36. https://doi. org/10.3892/ijmm.2019.4229.

30. Yang Y, Zhang P, Zhao YF, Yang J, Jiang GN, Fan J. Decreased MicroRNA26a expression causes cisplatin resistance in human non-small cell lung cancer. Cancer Biol Ther. 2016;17(5):515-25. https://doi.org/10.1080/ 15384047.2015.1095405.

31. Yang $X Y$, Zhao $Q$, Yin HL, Lei $X Y$, Gan RL. MiR-33b-5p sensitizes gastric cancer cells to chemotherapy drugs via inhibiting HMGA2 expression. $J$
Drug Target. 2017;25(7):653-60. https://doi.org/10.1080/1061186X.2017. 1323220.

32. Wang Y, Chen FQ, Zhao M, Yang Z, Zhang SQ, Ye LH, et al. MiR-107 suppresses proliferation of hepatoma cells through targeting HMGA2 mRNA 3'UTR. Biochem Biophys Res Commun. 2016;480(3):455-60. https://doi. org/10.1016/j.bbrc.2016.10.070.

33. Liu XZ, Yidayitula Y, Zhao H, Luo Y, Ma XQ, Xu MH. LncRNA LINC00152 promoted glioblastoma progression through targeting the miR-107 expression. Environ Sci Pollut Res Int. 2018;25(18):17674-81. https://doi. org/10.1007/s11356-018-1784-x.

34. Mansoori B, Mohammadi A, Ditzel HJ, Duijf PHG, Khaze V, Gjerstorff MF, et al. HMGA2 as a critical regulator in Cancer development. Genes (Basel). 2021;12(2):269. https://doi.org/10.3390/genes12020269.

35. Tan $L$, Wei XP, Zheng LX, Zeng JC, Liu HB, Yang SJ, et al. Amplified HMGA2 promotes cell growth by regulating Akt pathway in AML. J Cancer Res Clin Oncol. 2016;142(2):389-99 Https://doi.org/10.1007/ s00432-015-2036-9.

36. Wang YD, Mao JD, Wang JF, Xu MQ. MiR-590 suppresses proliferation and induces apoptosis in pancreatic cancer by targeting high mobility group A2. Technol Cancer Res Treat. 2020;19:1533033820928143. https://doi. org/10.1177/1533033820928143.

37. Robey RW, Pluchino KM, Hall MD, Fojo AT, Bates SE, Gottesman MM. Revisiting the role of $A B C$ transporters in multidrug-resistant cancer. Nat Rev Cancer. 2018;18(7):452-64. https://doi.org/10.1038/s41568-018-0005-8.

38. Song L, Zhou ZG, Gan YB, Li P, Xu Y, Zhang ZH, et al. Long noncoding RNA OIP5-AS1 causes cisplatin resistance in osteosarcoma through inducing the LPAATB/PI3K/AKT/mTOR signaling pathway by sponging the miR340-5p. J Cell Biochem. 2019;120(6):9656-66. https://doi.org/10.1002/jcb. 28244.

39. Ma Q, Chang ZH, Wang W, Wang BM. Rapamycin-mediated mTOR inhibition reverses drug resistance to adriamycin in colon cancer cells. Hepatogastroenterology. 2015;62(140):880-6.

40. Wang SF, Chou YC, Mazumder N, Kao FJ, Nagy LD, Guengerich FP, et al. 7-Ketocholesterol induces P-glycoprotein through PI3K/mTOR signaling in hepatoma cells. Biochem Pharmacol. 2013;86(4):548-60. https://doi. org/10.1016/j.bcp.2013.06.006.

\section{Publisher's Note}

Springer Nature remains neutral with regard to jurisdictional claims in published maps and institutional affiliations.

Ready to submit your research? Choose BMC and benefit from:

- fast, convenient online submission

- thorough peer review by experienced researchers in your field

- rapid publication on acceptance

- support for research data, including large and complex data types

- gold Open Access which fosters wider collaboration and increased citations

- maximum visibility for your research: over $100 \mathrm{M}$ website views per year

At BMC, research is always in progress.

Learn more biomedcentral.com/submissions 